\title{
BMJ
}

\section{Prognosis for patients with chronic low back pain: inception cohort study}

\author{
Luciola da C Menezes Costa, PhD candidate, ${ }^{1}$ Christopher G Maher, director of division, ${ }^{1}$ James H McAuley, \\ research manager, ${ }^{1,2}$ Mark J Hancock, lecturer, ${ }^{2}$ Robert D Herbert, associate professor, ${ }^{1}$ Kathryn M Refshauge, \\ professor, ${ }^{2}$ Nicholas Henschke, postdoctoral fellow ${ }^{1}$
}

\section{ABSTRACT}

Objectives To describe the course of chronic low back pain in an inception cohort and to identify prognostic markers at the onset of chronicity.

Design Inception cohort study with one year follow-up. Setting Primary care clinics in Sydney, Australia. Participants The study sample was a subcohort of an inception cohort of 973 consecutive patients presenting to primary care with acute low back pain ( 22 weeks' duration). 406 participants whose pain persisted for three months formed the inception cohort of patients with chronic low back pain.

Main outcome measures Outcomes and putative predictors measured at initial presentation, onset of chronicity (study entry), and follow-up at nine and 12 months. Recovery was determined from measures of pain intensity, disability, and work status. The association between potential prognostic factors and time to recovery was modelled with Cox regression. Results Completeness of follow-up was $97 \%$ of total person time for all outcomes. The cumulative probability of being pain-free was $35 \%$ at nine months and $42 \%$ at 12 months and for complete recovery was $35 \%$ at nine months and $41 \%$ at 12 months. Of the 259 participants who had not recovered from pain related disability at entry to the chronic study, $47 \%$ had recovered by 12 months. Previous sick leave due to low back pain, high disability levels or high pain intensity at onset of chronicity, low levels of education, greater perceived risk of persistent pain, and being born outside Australia were associated with delayed recovery.

Conclusion More than one third of patients with recent onset, non-radicular chronic low back pain recover within 12 months. The prognosis is less favourable for those who have taken previous sick leave for low back pain, have high disability levels or high pain intensity at onset of chronic low back pain, have lower education, perceive themselves as having a high risk of persistent pain, and were born outside Australia.

\section{INTRODUCTION}

Chronic low back pain (at least three months' duration $)^{1}$ is a major health problem, can be disabling, and imposes an enormous social and economic burden on the community. ${ }^{2}$ At any given time $12-33 \%$ of the adult population has low back pain. Estimates for one year prevalence range from $22 \%$ to $65 \%$ and for lifetime prevalence from $11 \%$ to $84 \% .^{3}$

The prognosis of chronic low back pain is uncertain. Although clinical guidelines generally portray the condition as having a poor prognosis ${ }^{14}$ this is based either on studies of potentially unrepresentative survival cohorts $^{56}$ or on studies with large losses to follow-up. ${ }^{78}$

Obtaining a representative cohort is the major problem in designing valid studies on the prognosis of chronic low back pain. ${ }^{9}$ Most studies follow survival cohorts, which sample prevalent cases. These cohorts are likely to over-represent people with longstanding disease and may therefore provide overly pessimistic estimates of prognosis. A more optimal design would be to take a sample from a population at risk of developing chronic low back pain and identify an inception cohort from incident cases. ${ }^{10}$

We examined a subcohort from a larger inception cohort of 973 people with acute low back pain presenting to primary care. ${ }^{11}$ The inception cohort included people at risk of developing chronic low back pain. Our primary aim was to determine the one year prognosis for patients with recent onset chronic low back pain. Our secondary aim was to identify prognostic markers at the onset of chronicity.

\section{METHODS}

The protocol for this study is published elsewhere. ${ }^{12}$ We studied an inception cohort of 406 patients with recent onset chronic non-specific low back pain. Participants were drawn from a larger cohort study of 973 consecutive patients with acute low back pain ( $<2$ weeks' duration) presenting to primary care clinics in Sydney, Australia. ${ }^{11} 13$ Multiple clinics were chosen to achieve a diverse range of socioeconomic characteristics among participants. We invited all clinicians (general practitioners, physiotherapists, and chiropractors) within the study area to participate in the study. Participating practitioners were trained to identify all eligible patients presenting at their clinics from November 2003 to July 2005. 


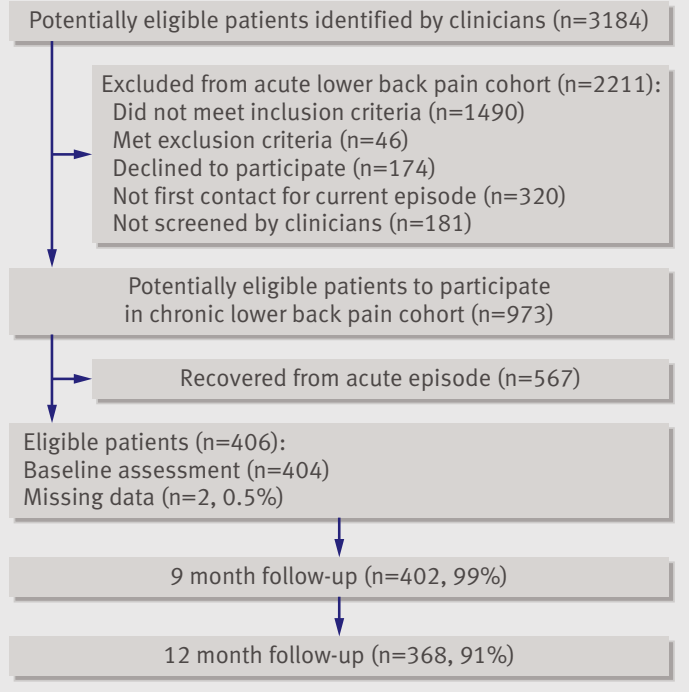

Fig 1| Flow of participants through study

To be eligible to participate in the larger cohort with acute low back pain ${ }^{11}$ the participants had to be at least 14 years old, provide written consent to participate in the study, speak and read English, and present with pain anywhere in the region of the low back bounded superiorly by T12 and inferiorly by the buttock crease, ${ }^{14}$ which had lasted for more than 24 hours but less than two weeks and had been preceded by at least one painfree month. ${ }^{15}$ Participants with pain that had persisted for three months after the onset of symptoms met the criteria for chronic low back pain and were invited to participate in the current study. We excluded patients with a diagnosis of radiculopathy or serious spinal disease, such as cancer, spinal infection, spinal fracture, and inflammatory arthritis. We gave the practitioners a copy of a clinical practice guideline for low back pain ${ }^{16}$ and asked them to follow it when appropriate.

\section{Clinical outcomes}

We measured three outcomes: intensity of pain, disability, and work status. The outcomes were assessed by telephone interview at the onset of chronic low back pain and nine and 12 months later. At both follow-up assessments, participants were asked whether they were pain-free, had no disability from back pain, and had returned to work in their previous capacity. When participants reported sustaining one of these outcomes for 30 consecutive days we considered them as "recovered" in that dimension on the first of the 30 days. ${ }^{15} \mathrm{~A}$ more stringent measure of recovery - complete recovery-required the patient to recover on all three of the pain, disability, and work status outcomes. The return to work outcome was irrelevant for participants who were not seeking work-for example, retirees.

We measured prognostic markers at the onset of both the acute episode and the onset of chronicity three months later. We selected specific markers considered to be associated with a poor outcome (see web extra on bmj.com). The markers were measures of sociodemographic characteristics, general health, current and previous low back pain, red flag symptoms or signs (features thought to be associated with serious spinal disease), pain intensity, disability, and psychological characteristics. We used adaptations of items 7 and 8 of the SF-36 to measure pain intensity and disability: How much low back pain have you had in the past week? and During the past week, how much did low back pain interfere with your normal work (including both work outside the home and housework) $?^{17}$ To keep the follow-up assessments suitable for interviewing a large cohort of patients by telephone, we used single items from validated questionnaires to assess predictors and outcomes.

\section{Statistical analysis}

We used Kaplan-Meier survival probability estimates to describe prognosis. Survival curves were constructed on the basis of the dates participants returned to work in their previous capacity, had no disability, or
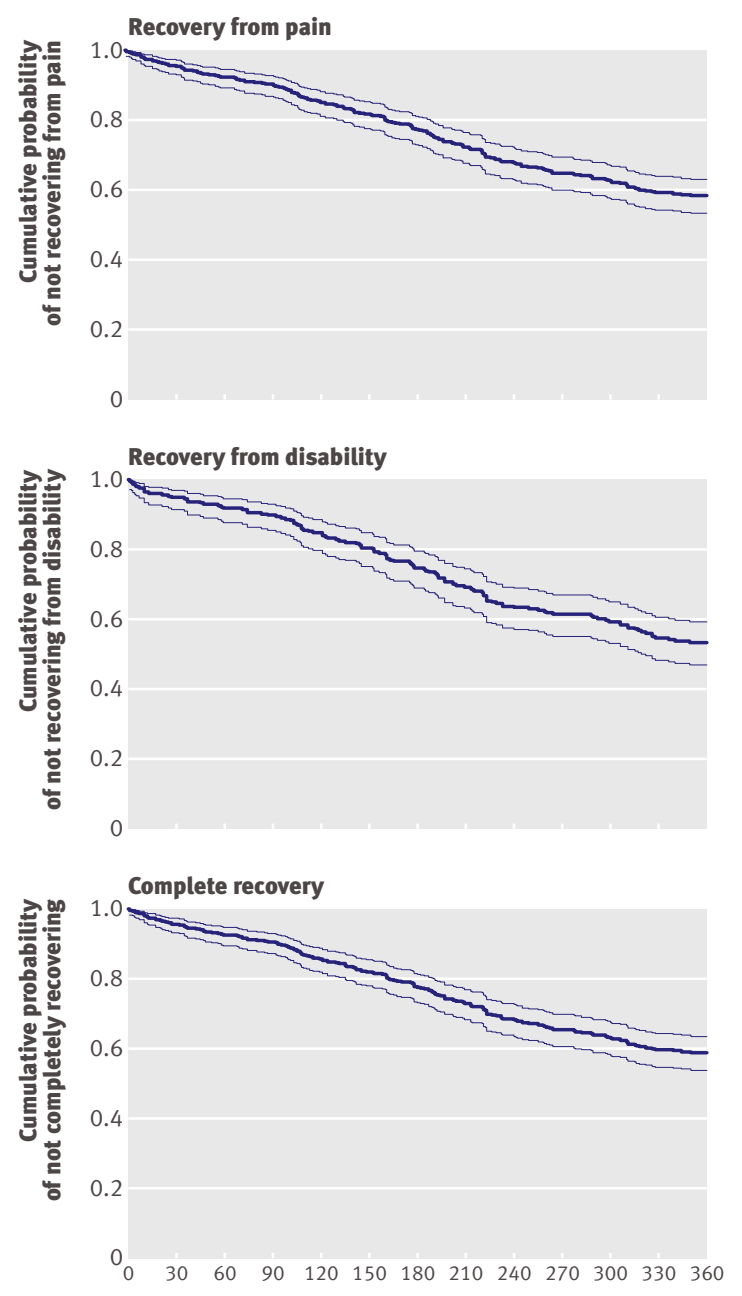

Days after onset of chronic low back pain

Fig 2 | Kaplan-Meier survival curves $(95 \%$ confidence intervals) of recovery from pain $(n=406)$ and disability $(n=259)$ and complete recovery $(n=406)$ 
Table 1 /Characteristics of study population. Values are numbers (percentages) unless stated otherwise

Variables

Participants $(n=406)$

Sociodemographic variables*:

\begin{tabular}{lc}
\hline Mean (SD) age (years) & $44.1(14.5)$ \\
\hline Male & $214(53)$ \\
\hline Born in Australia & $277(68)$ \\
\hline Aboriginal and Torres Strait Islander peoples & $5(1)$ \\
\hline No education beyond secondary schoolt & $238(59)$ \\
\hline Smoker & $84(21)$ \\
\hline Worked before injury & $325(80)$ \\
\hline Work status changed as result of low back pain $(\mathrm{n}=325)$ & $137(42)$ \\
\hline Exercises regularly & $235(58)$ \\
\hline Primary care clinician*: & $85(21)$ \\
\hline General practitioner & $312(77)$ \\
\hline Physiotherapist & $9(2)$ \\
\hline Chiropractor
\end{tabular}

Self rated health*:

\begin{tabular}{|c|c|}
\hline Poor & 0 \\
\hline Fair & $34(8)$ \\
\hline Good & $156(39)$ \\
\hline Very good & $141(35)$ \\
\hline Excellent & 75 (19) \\
\hline \multicolumn{2}{|l|}{ Details of low back pain*: } \\
\hline Previous episode & $314(77)$ \\
\hline Previous sick leave & $162(40)$ \\
\hline Previous surgery & $14(3)$ \\
\hline Sudden onset & $325(80)$ \\
\hline Compensation case $\neq$ & $104(26)$ \\
\hline Currently taking medication for low back pain & $185(46)$ \\
\hline Leg pain & $107(26)$ \\
\hline \multicolumn{2}{|l|}{ Pain intensity§: } \\
\hline None & $34(8)$ \\
\hline Very mild & $112(28)$ \\
\hline Mild & $134(33)$ \\
\hline Moderate & $101(25)$ \\
\hline Severe & $23(6)$ \\
\hline Missing data & $2(0.5)$ \\
\hline \multicolumn{2}{|l|}{ Disability§: } \\
\hline Not at all & $172(42)$ \\
\hline Little bit & $116(29)$ \\
\hline Moderate & $81(20)$ \\
\hline Quite a bit & $32(8)$ \\
\hline Extreme & $3(1)$ \\
\hline Missing data & $2(0.5)$ \\
\hline
\end{tabular}

*Collected at beginning of acute episode of low back pain.

†In Australia, after 13 years of schooling.

$\ddagger$ Worker's compensation and third party motor vehicle insurance cases.

§Based on modified items 7 and 8 from SF-36 (original wording changed from bodily pain to low back pain to reflect our specific interest): "How much low back pain have you had in the past week?" and "During the past week, how much did low back pain interfere with your normal work (including work outside the home and housework)?" These data were collected an average of 99.8 days (SD 10.58) from onset of acute low back pain.

were free of pain. We censored participants for whom follow-up data were incomplete or who did not recover from their pain, at the time of their last follow-up. Completeness of follow-up was calculated using the completeness index. ${ }^{18}$ This index is the ratio of the total observed person time of follow-up as a percentage of the potential time of follow-up in a study. The numerator is the sum of follow-up times, irrespective of whether the event took place or survival time was censored, and the denominator is the sum of the potential follow-up times. A completeness index value of $100 \%$ indicates complete follow-up.

We used the log rank test ${ }^{1920}$ to identify associations between each possible prognostic marker and the time to recovery from pain and disability. Markers with significant associations $(\mathrm{P}<0.20)$ were selected for possible inclusion in a Cox regression model. Where any correlation between the significant variables was greater than 0.6 we selected one based on strength of association and ease of assessment. Multivariate survival analyses were done using backward elimination to specify a model in which all variables had statistical significance $(\mathrm{P}<0.05)$. We verified the proportional hazard assumption by plotting the Schoenfeld residuals and found no important violation for any variable. Data were analysed using SAS version 9.1.

\section{RESULTS}

Between November 2003 and July 2005 a total of 3184 consecutive patients with low back pain were screened by 170 trained clinicians (73 general practitioners, 77 physiotherapists, and 20 chiropractors). Of these patients, 973 who had non-specific low back pain for less than two weeks agreed to participate in the larger cohort of acute low back pain. ${ }^{11}$ Overall, 406 patients had not recovered by three months and agreed to join the inception cohort study of recent onset chronic low back pain (fig 1$)$. Few data $(0.1 \%)$ on prognostic markers were missing. In total, 377 patients $(93 \%)$ were successfully followed up until they recovered or were censored at the time of their last follow-up. The remaining 29 patients were censored early. Completeness of followup was $97 \%$ of person time. ${ }^{18}$ Table 1 shows the baseline characteristics of the study population.

Figure 2 presents the Kaplan-Meier survival curves for the three outcomes. As the estimated survival did not fall below $50 \%$, 25th centile survival times are presented: 178 days (95\% confidence interval 153 to 209 ) for disability, 192 (170 to 222) for pain, and 197 (176 to 223) for complete recovery. The cumulative probability of being pain-free was 35\% (141 events) at nine months and $42 \%$ (165 events) at 12 months. Of the 259 participants who had not recovered from pain related disability at entry to the chronic study, 39\% (99 events) had recovered by nine months and 47\% (118 events) by 12 months. The cumulative probability of complete recovery was 35\% (139 events) at nine months and 41\% (163 events) at 12 months (fig 2). Only 44 of 406 participants $(11 \%)$ had not returned to work in their previous capacity at the onset of chronicity and, of these, $46 \%$ (20 events) had returned to work in their previous capacity by 12 months.

Table 2 shows the characteristics of the study population for pain intensity, pain related disability, and work status at the onset of symptoms (acute presentation), study entry (onset of chronicity), and the followup assessments. At the onset of chronicity the cohort had relatively low levels of pain and disability-for 
Table 2 | Pain, disability, and work status of 380 participants. ${ }^{*}$ Values are numbers (percentages)

\begin{tabular}{|c|c|c|c|c|c|}
\hline Outcomes & Pre-episode & $\begin{array}{l}\text { Onset of symptoms: } \\
\text { acute presentation }\end{array}$ & $\begin{array}{c}\text { Study entry: } \\
\text { onset of chronicity }\end{array}$ & 9 months & 12 months \\
\hline \multicolumn{6}{|l|}{ Pain† } \\
\hline None & - & 0 & $31(8)$ & $121(32)$ & $142(37)$ \\
\hline Very mild & - & $3(1)$ & $105(28)$ & 71 (19) & $44(12)$ \\
\hline Mild & - & $26(7)$ & $125(33)$ & $83(22)$ & $98(26)$ \\
\hline Moderate & - & $111(29)$ & $96(25)$ & $82(22)$ & $77(20)$ \\
\hline Severe & - & $195(51)$ & $22(6)$ & $16(4)$ & $7(2)$ \\
\hline Very severe & - & $45(12)$ & 0 & $3(1)$ & 0 \\
\hline Missing data & - & 0 & $1(0.3)$ & $4(1)$ & $12(3)$ \\
\hline \multicolumn{6}{|l|}{ Disability† } \\
\hline Not at all & - & $18(5)$ & $161(42)$ & 223 (59) & $238(63)$ \\
\hline Little bit & - & $42(11)$ & $113(30)$ & $75(20)$ & $79(21)$ \\
\hline Moderate & - & 72 (19) & 72 (19) & $61(16)$ & $40(11)$ \\
\hline Quite a bit & - & $152(40)$ & $30(8)$ & $16(4)$ & $9(2)$ \\
\hline Extreme & - & $96(25)$ & $3(1)$ & $1(0.3)$ & $2(0.5)$ \\
\hline Missing data & - & 0 & $1(0.3)$ & $4(1)$ & $12(3)$ \\
\hline \multicolumn{6}{|l|}{ Work status } \\
\hline Employed: & - & & & & \\
\hline Full duties & $289(76)$ & $164(43)$ & $254(67)$ & $265(70)$ & $260(69)$ \\
\hline Selected duties & $15(4)$ & $59(16)$ & $39(10)$ & $21(6)$ & $23(6)$ \\
\hline Sick leave & $5(1)$ & $78(21)$ & $11(3)$ & $10(3)$ & $6(2)$ \\
\hline Maternity or long service leaveł & $4(1)$ & $6(2)$ & $3(1)$ & $4(1)$ & $2(0.5)$ \\
\hline Unemployed & $12(3)$ & $16(5)$ & $16(4)$ & $16(4)$ & $15(4)$ \\
\hline Not seeking paid employment & $53(14)$ & $54(14)$ & $54(14)$ & $57(15)$ & $58(15)$ \\
\hline Other & $2(0.5)$ & $2(0.5)$ & $2(0.5)$ & $3(1)$ & $4(1)$ \\
\hline Missing data & 0 & 0 & $1(0.3)$ & $4(1)$ & $12(3)$ \\
\hline \multicolumn{6}{|c|}{$\begin{array}{l}\text { * } 26 \text { participants did not complete } 12 \text { month assessment. Participants with incomplete follow-up were not significantly different from those with } \\
\text { complete follow-up for pain }(P=0.98) \text {, pain related disability }(P=0.96) \text {, and work status }(P=0.60) \text {. } \\
\text { †Based on modified items } 7 \text { and } 8 \text { from SF- } 36 \text { (original wording changed from bodily pain to low back pain to reflect our specific interest): "How } \\
\text { much low back pain have you had in the past week?" and "During the past week, how much did low back pain interfere with your normal work } \\
\text { (including work outside the home and housework)?"These data were collected an average of } 99.8 \text { days (SD 10.58) from onset of acute low back pain } \\
\text { †Additional paid leave for longstanding employees in Australia and New Zealand. }\end{array}$} \\
\hline
\end{tabular}

example, around two thirds reported pain levels as "mild" or less and disability levels as a "little bit" or less. At nine months, 32\% $(\mathrm{n}=121)$ of participants reported being free of pain and $59 \%(n=223)$ free of pain related disability; respective values at 12 months were $37 \%(n=142)$ and $63 \%(n=238)$. Before the onset of the acute episode of low back pain, $76 \%(n=289)$ of the participants were working full time; this value had decreased to $43 \%(n=164)$ at the onset of acute low back pain. At the onset of chronicity, 88\% (254/289) of the participants who were employed before the onset of the acute episode had returned to work.

See web extra on bmj.com for the full results of univariate Cox regression analysis. Table 3 lists the variables associated with time to recovery from pain. The correlations between the variables feelings of depression and feelings of tension or anxiety and between the variables pain intensity and disability at chronic presentation were greater than 0.6 (Pearson's $r=0.65$ for both correlations). Based on ease of assessment and on the univariate hazard ratio, the variables feelings of tension or anxiety and pain intensity were excluded from the multivariate analysis. Of the 15 variables entered into the multivariate model, Cox regression showed that only previous sick leave due to low back pain (likelihood ratio $\chi_{1}^{2}=4.9, \mathrm{P}=0.03$ ), high disability levels at chronic presentation $\left(\chi_{1}^{2}=20.1, \mathrm{P}<0.001\right)$, low level of education $\left(\chi_{1}^{2}=3.8, \mathrm{P}=0.05\right)$, and greater perceived risk of persistent pain $\left(\chi^{2}{ }_{1}=10.0, \mathrm{P}=0.002\right)$ were significantly associated with delayed recovery. The adjusted hazard ratio for previous sick leave due to low back pain was 0.69 (95\% confidence interval 0.50 to 0.97 ) and for low level of education was 0.74 (0.54 to 1.00). Therefore participants who had taken previous sick leave due to low back pain and those with no education beyond secondary school were $31 \%$ and $26 \%$, respectively, less likely to recover from pain at any time in the future compared with those without these characteristics. The adjusted hazard ratio for disability level was 0.68 (0.56 to 0.81 ) and for perceived risk of persistent pain was 0.91 (0.86 to 0.97$)$. As these variables are continuous the interpretation is that for every unit increase in these scales, participants are $32 \%$ and $9 \%$ less likely, respectively, to recover from pain at some time in the future.

Table 4 lists the variables associated with time to recovery from disability. Owing to the high correlation between the variables feelings of tension or anxiety and 
Table 3 Unadjusted and adjusted effects of variables on time to recovery from chronic low back pain $(\mathrm{n}=402)$

\begin{tabular}{|c|c|c|c|}
\hline Variables & Crude hazard ratio $(95 \% \mathrm{Cl})$ & $P$ value & Adjusted hazard ratio $(95 \% \mathrm{Cl})$, $\mathrm{P}$ value \\
\hline Lower half of socioeconomic index* & $0.75(0.53$ to 1.06$)$ & 0.11 & \\
\hline No education beyond secondary school $\dagger$ & 0.65 (0.48 to 0.88$)$ & 0.006 & $0.74(0.54$ to 1.00$) \ddagger, 0.05$ \\
\hline Current smoker & $0.74(0.49$ to 1.11$)$ & 0.14 & \\
\hline Self rated general health§ & $0.86(0.72$ to 1.03$)$ & 0.10 & \\
\hline Compensable low back pain & $0.60(0.41$ to 0.88$)$ & 0.01 & \\
\hline Currently taking medication for low back pain & $0.67(0.49$ to 0.92$)$ & 0.01 & \\
\hline Pain intensity at acute presentation $\mathbb{T}$ & $0.85(0.70$ to 1.04$)$ & 0.11 & \\
\hline Disability at acute presentation ${ }^{\star *}$ & $0.89(0.78$ to 1.02$)$ & 0.09 & \\
\hline Work status changed due to low back pain & 0.78 (0.56 to 1.09$)$ & 0.15 & \\
\hline Previous sick leave due to low back pain & $0.63(0.45$ to 0.87$)$ & 0.005 & $0.69(0.50$ to 0.97$) \dagger \dagger, 0.03$ \\
\hline Feelings of depressionł‡ & $0.92(0.87$ to 0.96$)$ & 0.0004 & \\
\hline Tension or anxietyłł & $0.93(0.88$ to 0.99$)$ & 0.01 & \\
\hline Risk of persistent pain $\ddagger \ddagger$ & $0.88(0.84$ to 0.93$)$ & $<0.001$ & 0.91 (0.86 to 0.97$) \S \S, 0.002$ \\
\hline \multicolumn{4}{|l|}{ Red flag symptoms: } \\
\hline Systemically unwell & 1.93 (0.91 to 4.12$)$ & 0.08 & \\
\hline Back stiffness in morning ( $\geq 0.5$ hours) & $0.66(0.45$ to 0.97$)$ & 0.03 & \\
\hline Pain intensity at chronic presentationđ & 0.68 (0.59 to 0.79$)$ & $<0.001$ & \\
\hline Disability at chronic presentation ${ }^{\star \star}$ & $0.63(0.53$ to 0.75$)$ & $<0.001$ & 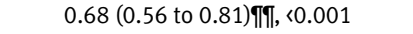 \\
\hline
\end{tabular}

*Based on data from Australian census, indicates that postcode socioeconomic index was below national mean-that is, lower socioeconomic status. †In Australia after 13 years of schooling.

$\ddagger$ Adjusted for previous sick leave due to low back pain, risk of persistent pain, and pain related disability.

$\S$ Rated on scale from $0=$ poor to $5=$ excellent.

TPain intensity scale: $1=$ none, $2=$ very mild, $3=$ mild, $4=$ moderate, $5=$ severe, $6=$ very severe

${ }^{*}$ Disability scale: $1=$ not at all, $2=$ a little bit, $3=$ moderately, $4=$ quite a bit, $5=$ extremely.

††Adjusted for education, risk of persistent pain, and pain related disability at chronic presentation.

$\ddagger \ddagger$ Rated on scales from $0-10$, with higher scores indicating more tension and anxiety, more feelings of depression, or higher risk of persistent pain.

$\S \S$ Adjusted for previous sick leave due to low back pain, education, and pain related disability at chronic presentation.

TTTAdjusted for education, previous sick leave due to low back pain, and risk of persistent pain at chronic presentation.

depression (Pearson's r $=0.66$ ) and between pain intensity and disability (Pearson's $\mathrm{r}=0.65$ ) these were excluded from the multivariate model. Of the 15 variables entered into the multivariate model, Cox regression showed that only high levels of disability at chronic presentation (likelihood ratio $\chi_{1}^{2}=13.5$, $\mathrm{P}=0.0003)$, greater perceived risk of persistent pain $\left(\chi_{1}^{2}=17.0, \mathrm{P}<0.0001\right)$, and being born outside Australia $\left(\chi_{1}^{2}=10.7, \mathrm{P}=0.001\right)$ were significantly associated with delayed recovery as a result of disability. The adjusted hazard ratio for participants born outside Australia was 0.51 (95\% confidence interval 0.33 to 0.78$)$. Therefore participants who were born outside Australia were $49 \%$ less likely at some time in the future to recover from disability than those who were born in Australia. The adjusted hazard ratio for disability level was 0.69 (0.57 to 0.85 ) and for perceived risk of persistent pain was 0.88 (0.82 to 0.94$)$. As disability level and perceived risk of persistent pain are continuous variables, for every unit increase in these scales participants were $31 \%$ and $12 \%$ less likely, respectively, to recover from disability at some time in the future.

Because of the strong association between the variable pain intensity and delayed recovery in terms of pain and disability the regression analysis was repeated in both models with the variable pain intensity instead of the variable disability. This sensitivity analysis showed that the same set of variables (previous sick leave due to low back pain, low level of education, greater perceived risk of persistent pain, and being born outside Australia) plus higher pain intensity were significantly associated with delayed recovery owing to pain and disability. The adjusted hazard ratio for pain intensity in the pain model was 0.73 (0.62 to 0.85$)$ and in the disability model was 0.78 (0.66 to 0.92 ). The adjusted hazard ratios for the other predictors were similar to the primary multivariate analysis (tables 3 and 4).

\section{DISCUSSION}

The rate of recovery from non-radicular chronic low back pain in a representative inception cohort from a primary care setting was much higher than previously reported. ${ }^{5-7}$ Overall, 35\% of patients had recovered completely by nine months and $41 \%$ by 12 months. Contrary to the view that recovery from an episode of chronic low back pain is unlikely, ${ }^{1521-23}$ we found that an important proportion of patients recovered within one year. Both at onset of chronicity and at 12 months most participants reported low levels of pain and disability. Patients with high disability levels or high intensity of pain at presentation for chronic low back pain, previous sick leave due to low back pain, a lower level of education, and higher perceived risk of persistent pain were more likely to have delayed recovery from their pain. Participants with high disability levels or high pain intensity at presentation for chronic low back pain, higher perceived risk of persistent pain, and who were born outside Australia were more likely to have delayed recovery from their disability. 
Table 4 Unadjusted and adjusted effects of variables on time to recovery from low back pain related disability $(n=256)$

\begin{tabular}{|c|c|c|c|}
\hline Variables & Crude hazard ratio $(95 \% \mathrm{Cl})$ & $P$ value & Adjusted hazard ratio $(95 \% \mathrm{Cl}), \mathrm{P}$ value \\
\hline Born outside Australia & $0.58(0.38$ to 0.89$)$ & 0.01 & $0.51(0.33 \text { to } 0.78)^{\star}, 0.001$ \\
\hline No education beyond secondary school† & $0.72(0.50$ to 1.03$)$ & 0.07 & \\
\hline Current smoker & $0.64(0.39$ to 1.04$)$ & 0.07 & \\
\hline Compensable low back pain & $0.56(0.37$ to 0.87$)$ & 0.009 & \\
\hline Taking medication for low back pain & 0.71 (0.50 to 1.03$)$ & 0.07 & \\
\hline Presence of leg pain & $0.76(0.50$ to 1.14$)$ & 0.18 & \\
\hline Pain intensity at acute presentation $\ddagger$ & 0.78 (0.63 to 0.98$)$ & 0.03 & \\
\hline Interference with function due to low back pain§ & $0.89(0.76$ to 1.04$)$ & 0.13 & \\
\hline Previous sick leave due to low back pain & $0.70(0.48$ to 1.02$)$ & 0.06 & \\
\hline Tension or anxiety & $0.94(0.87$ to 1.01$)$ & 0.08 & \\
\hline Feelings of depression $\mathbb{T}$ & $0.92(0.87$ to 0.98$)$ & 0.007 & \\
\hline Risk of persistence & $0.88(0.82$ to 0.94$)$ & $<0.001$ & $0.88(0.82 \text { to } 0.94)^{\star \star},<0.001$ \\
\hline \multicolumn{4}{|l|}{ Red flag signs: } \\
\hline Insidious onset & 1.41 (0.89 to 2.23$)$ & 0.15 & \\
\hline Major trauma & $1.76(0.82$ to 3.77$)$ & 0.15 & \\
\hline $\begin{array}{l}\text { Persisting limitation of spinal movements in all } \\
\text { directions }\end{array}$ & $0.66(0.35$ to 1.23$)$ & 0.19 & \\
\hline Pain intensity at chronic presentation $\ddagger$ & $0.77(0.65$ to 0.91$)$ & 0.002 & \\
\hline Disability at chronic presentation§ & $0.67(0.55$ to 0.82$)$ & 0.0001 & 0.69 (0.57 to 0.85$) \dagger \dagger, 0.0002$ \\
\hline
\end{tabular}

${ }^{*}$ Adjusted for risk of persistence and disability at chronic presentation.

†In Australia after 13 years of schooling.

$\ddagger$ Pain intensity scale: $1=$ none, $2=$ very mild, $3=$ mild, $4=$ moderate, $5=$ severe, $6=$ =very severe.

$\S$ Disability scale: $1=$ not at all, $2=a$ little bit, $3=$ moderately, $4=$ quite a bit, $5=$ =xtremely.

TRated on scales from 0-10, with higher scores indicating more tension and anxiety, more feelings of depression, or higher risk of persistent pain.

${ }^{\star \star}$ Adjusted for being born outside Australia and pain related disability at chronic presentation.

$\dagger \dagger$ Adjusted for being born outside Australia and risk of persistent pain.

\section{Strengths and weaknesses of the study}

An important strength of our study was that we enrolled an inception cohort from the three main clinicians (general practitioners, physiotherapists, and chiropractors) who manage low back pain in primary care. We measured intensity of pain, pain related disability, and work status over 12 months, with near complete follow-up (97\%). In addition we recruited participants using a strict definition for chronic and acute low back pain and used a clear definition of recovery. ${ }^{15}$ Another strength of this study was that we measured the prognostic markers for the initial acute episode at the time of the episode rather than relying on recall. A limitation of the study was that we were unable to measure prognostic outcomes blinded to the prognostic markers as measures of both outcomes and prognostic markers were self reported.

\section{Strengths and weaknesses in relation to other studies}

Although many studies provide good evidence for the prognosis of acute low back pain, ${ }^{1124-26}$ relatively few provide good evidence for the prognosis of chronic low back pain. Most studies have sampled prevalent cases of chronic low back pain, ${ }^{5621}$ which potentially introduces bias because the prognosis of people with longstanding disease is likely to be different from that of people with a newly developed condition. ${ }^{27}$ Even where researchers aim to enrol an inception cohort by following patients with acute back pain until they develop chronic back pain, difficulties can arise with sampling consecutive incident cases of chronic low back pain. ${ }^{28}$ Sampling is best achieved by following the original cohort with acute pain to the time of onset of chronic status (three months), and then recruiting all those who developed chronic pain. In our study we followed $99 \%$ of the cohort with acute pain to three months and then recruited all patients who developed chronic pain, so we are confident that we enrolled a representative inception cohort with chronic low back pain. In comparison, another study lost one quarter of the original cohort with acute pain. ${ }^{7}$ This may explain why our estimate of prognosis is more optimistic than that of the other study $-41 \%$ of participants in our study had recovered from pain by 12 months compared with only $16 \%$ by 22 months in the other study. ${ }^{7}$ This pattern fits with our understanding of the effect of enrolling a survival cohort rather than an inception cohort. $^{9}$

Another major difference between the studies is the proportion of participants who developed chronic low back pain; $42 \%$ in our study compared with $8 \%{ }^{7} \mathrm{~A}$ recent systematic review on the prognosis of acute low back pain ${ }^{29}$ concluded that pain decreased rapidly within one month (pooled mean 58\%), with pain intensity continuing to decrease slowly up to three months and then remain constant until 12 months, which is a similar finding to our parent study. ${ }^{11}$

The baseline characteristics of our inception cohort and the outcomes may differ from those of previous cohorts formed from patients with chronic low back 


\section{WHAT IS ALREADY KNOWN ON THIS TOPIC}

Chronic low back pain is a major health problem in most societies

Its course has not been well investigated, however, because of difficulties in obtaining a representative sample

\section{WHAT THIS STUDY ADDS}

For people with recent onset chronic low back pain, 35\% will recover by nine months and $41 \%$ by 12 months

Previous sick leave, high disability levels, high levels of pain, low levels of education, greater perceived risk of persistent pain, and being born overseas were associated with delayed recovery
We thank Anurina Das for assistance in data collection and Laurent Billot for statistical advice.

Contributors: CGM, KMR, and RDH were the chief investigators on the NHMRC project grant that funded the study. CGM, JHMCA, KMR, and NH trained the recruiting clinicians. JHMcA and NH carried out the follow-up assessments and entered the data. LdaCMC double checked the data. All authors contributed to the study design and the analysis and interpretation of the data and reviewed and approved the final version of the manuscript. CGM is the guarantor.

Funding: This study was supported by a grant from the National Health and Medical Research Council of Australia. The funder had no role in the study design; collection, analysis, and interpretation of data; writing of the report; or decision to submit the article for publication. The National Health and Medical Research Council of Australia funds the research fellowships of CGM, RDH, and $\mathrm{NH}$.

Competing interests: None declared

Ethical approval: This study was approved by the University of Sydney human research ethics committee.

pain attending clinical settings ${ }^{530}$ (that is, patients who seek care for their chronic low back pain). Samples obtained from the population of those with chronic low back pain (survivor cohorts) tend to over-represent those who have had the condition for a long time, which may introduce bias. Recruiting patients with chronic low back pain at a uniform point in the course of the disease is preferable as such samples (inception cohorts) are not exposed to the biases inherent in studies of survivor cohorts. The levels of pain and disability that were observed at the onset of chronicity in this inception cohort were lower than those reported in survival cohorts of patients seeking care for low back pain. ${ }^{56}$

The secondary aim of this study was to identify patient characteristics associated with poor prognosis of recent onset chronic low back pain. Patients with high disability levels or high pain intensity at presentation for chronic low back pain, previous sick leave due to low back pain, a lower level of education, and greater perceived risk of persistent pain were more likely to experience delayed recovery from pain than those without these characteristics. Similar prognostic markers were associated with delayed recovery from disability (high disability levels or high pain intensity at presentation for chronic low back pain, greater perceived risk of persistent pain, and being born outside Australia). The most obvious use of this information is to provide individual specific estimates of prognosis for patients in primary care. This information is, however, new and needs to be validated in future studies. Further studies are needed to test the generalisability of these prognostic markers in other inception cohorts of patients with chronic low back pain in primary care.

\section{Conclusions}

Our findings suggest that the prognosis is moderately optimistic for patients with chronic low back pain. Patients with recent onset, non-radicular chronic low back pain can be reassured that they have a good chance of recovery. The prognosis is less favourable for those who have taken previous sick leave for low back pain, have high disability levels or high pain intensity at onset of chronic low back pain, have lower education, perceive themselves as having a high risk of persistent pain, and were born outside Australia.
1 Airaksinen 0, Brox JI, Cedraschi C, Hildebrandt J, Klaber-Moffett J, Kovacs F, et al. European guidelines for the management of chronic nonspecific low back pain. Eur Spine J 2006;15:S192-300.

2 Mounce K. Back pain. Rheumatology 2002;41:1-5.

3 Walker BF. The prevalence of low back pain: a systematic review of the literature from 1966 to 1998. J Spinal Disord 2000;13:205-17.

4 Koes BW, van Tulder MW, Ostelo R, Kim Burton A, Waddell G. Clinical guidelines for the management of low back pain in primary care: an international comparison. Spine 2001;26:2504-13.

5 Van Tulder MW, Koes BW, Metsemakers JF, Bouter LM. Chronic low back pain in primary care: a prospective study on the management and course. Fam Pract 1998;15:126-32.

6 Van Tulder MWP, Koes BWP, Bouter LMP, Metsemakers JF. Management of chronic nonspecific low back pain in primary care: a descriptive study. Spine 1997;22:76-82.

7 Carey TS, Garrett JM, Jackman AM. Beyond the good prognosis: examination of an inception cohort of patients with chronic low back pain. Spine 2000;25:115-20.

8 Grotle M, Vollestad NK, Brox JI. Clinical course and impact of fearavoidance beliefs in low back pain: prospective cohort study of acute and chronic low back pain II. Spine 2006;31:1038-46.

9 Altman DG. Systematic reviews of evaluations of prognostic variables. $B M / 2001 ; 323: 224-8$.

10 Fletcher RH, Wagner EH. Clinical epidemiology: the essentials. 3rd ed. Baltimore, MD: Williams \& Wilkins, 1996.

11 Henschke N, Maher CG, Refshauge KM, Herbert RD, Cumming RG, Bleasel J, et al. Prognosis in patients with recent onset low back pain in Australian primary care: inception cohort study. BMJ 2008;337:a171.

12 Costa LdCM, Henschke N, Maher CG, Refshauge KM, Herbert RD, McAuley JH, et al. Prognosis of chronic low back pain: design of an inception cohort study. BMC Musculoskelet Disord 2007;8:11.

13 Henschke N, Maher CG, Refshauge KM, Herbert RD, Cumming RG, Bleasel J, et al. Prognosis of acute low back pain: design of a prospective inception cohort study. BMC Musculoskelet Disord 2006;7:54

14 Watson KD, Papageorgiou AC, Jones GT, Taylor S, Symmons DPM, Silman AJ, et al. Low back pain in schoolchildren: the role of mechanical and psychosocial factors. Arch Dis Child 2003;88:12-7.

15 De Vet HCW, Heymans MW, Dunn KM, Pope DP, van der Beek AJ, Macfarlane GJ, et al. Episodes of low back pain: a proposal for uniform definitions to be used in research. Spine 2002;27:2409-16.

16 National Health and Medical Research Council. Evidence-based management of acute musculoskeletal pain. Canberra: NHMRC, 2003.

17 Ware JE Jr, Sherbourne CD. The MOS 36-item short-form health survey (SF-36): I. Conceptual framework and item selection. Med Care 1992;30:473-83.

18 Clark TG, Altman DG, De Stavola BL. Quantification of the completeness of follow-up. Lancet 2002;359:1309-10.

19 Bland JM, Altman DG. The logrank test. BMJ 2004;328:1073.

20 Peto R, Pike MC, Armitage P. Design and analysis of randomised clinical trials requiring prolonged observation of each patient: II. Analysis and examples. Br/ Cancer 1977;35:1-39.

21 Carey TS, Evans A, Hadler N, Kalsbeek W, McLaughlin C, Fryer J. Care seeking among individuals with chronic low back pain. Spine 1995;20:312-7.

22 Von Korff M, Saunders K. The course of back pain in primary care. Spine 1996;21:2833-7.

23 Croft PR, Macfarlane GJ, Papageorgiou AC, Thomas E, Silman AJ. Outcome of low back pain in general practice: a prospective study. BMJ 1998;316:1356-9. 
24 Carey TS, Garrett J, Jackman A, McLaughlin C, Fryer J, Smucker DR, et al. The outcomes and costs of care for acute low-back-pain among patients seen by primary-care practitioners, chiropractors, and orthopedic surgeons. N Engl J Med 1995;333:913-7.

25 Coste J, Delecoeuillerie G, Cohen de Lara A, Le Parc JM, Paolaggi JB. Clinical course and prognostic factors in acute low back pain: an inception cohort study in primary care practice. $B M J$ 1994;308:577-80.

26 Schiottz-Christensen B, Nielsen GL, Hansen VK, Schodt T, Sorensen HT, Olesen F. Long-term prognosis of acute low back pain in patients seen in general practice: a 1-year prospective follow-up study. Fam Pract 1999;16:223-32.
27 Mak K, Kum CK. How to appraise a prognostic study. World J Surg 2005;29:567-9.

28 Herbert R, Jamtvedt G, Mead J, Hagen KB. Practical evidence-based physiotherapy. London: Elsevier's Health Sciences, 2005.

29 Pengel LHM, Herbert RD, Maher CG, Refshauge KM. Acute low back pain: systematic review of its prognosis. BMJ 2003;327:323-5.

30 Van den Hoogen HJ, Koes BW, Deville W, van Eijk JT, Bouter LM. The prognosis of low back pain in general practice. Spine 1997;22:1515-21.

Accepted: 29 June 2009 